\title{
ŚRODKI SŁUŻĄCE FORMULOWANIU CHIŃSKICH PRZEPISÓW NOWELIZUJĄCYCH, ODSYLAJĄCYCH, UCHYLAJĄCYCH, PRZEPISÓW O WEJŚCIU USTAWY W ŻYCIE I O ZAKRESIE ZASTOSOWANIA
}

\author{
Joanna GRZYBEK, dr \\ Instytut Językoznawstwa, Uniwersytet im. A. Mickiewicza \\ al. Niepodległości 4, 61-874 Poznań \\ joanna.grzybek@gmail.com
}

\begin{abstract}
Abstrakt: Celem artykułu jest wyodrębnienie chińskich środków językowych zastosowanych w wybranych przepisach ustawowych, które pozwalają na zachowanie przejrzystej konstrukcji aktów prawotwórczych i ich komunikatywności. Ponieważ autorka nie znalazła wśród chińskich regulacji dotyczących podstawowych zasad legislacji typologii przepisów i stosowanych $\mathrm{w}$ nich środków językowych, postanowiła odnaleźć je w wybranych chińskich przepisach i przetłumaczyć na język polski.

W tym celu autorka dokonała analizy tekstów paralelnych w oparciu o pragmatyczny model thumaczenia terminów prawnych Kierzkowskiej. Korpus badawczy stanowily fragmenty aktów prawotwórczych polskich i chińskich, zawierające przepisy nowelizujące, odsyłające, uchylające, przepisy o wejściu ustawy w życie i przepisy o zakresie zastosowania.

Wyniki przeprowadzonej analizy pozwalają stwierdzić, że chiński ustawodawca tworząc przepisy stosuje swoisty i mało rozbudowany katalog środków językowych. Autorka przedstawiła je w niniejszym artykule.
\end{abstract}

\section{CHINESE EXPRESSIONS AND VERB PHRASES \\ IN AMENDING, REFERENCE, DEROGATIVE, COMMENCEMENT AND EXTENT CLAUSES}

\begin{abstract}
The aim of the article is to find Chinese expressions and verb phrases used in selected statutory instruments, which provide a transparent structure of statutory instruments and communicativeness. Since the author has not found the typology of statutory clauses and the most commonly used expressions and verb phrases in Chinese legislative regulations, she has found them in selected Chinese statutory clauses and has translated them into Polish.

The author analyzed the selected parallel texts applying the model of pragmatic translation of legal terms described by Kierzkowska. The corpora of Polish and Chinese statutory instruments encompass the following: amending clauses, reference clause, derogative clause, commencement clause and extent clauses. The results of the analyses indicate, that the Chinese legislator applies an specific and not very elaborate catalogue of expressions and verb phrases when creating statutory instruments. The author presents the most commonly used expressions and verb phrases which may be found in investigated Chinese statutory clauses.
\end{abstract}

Słowa kluczowe: język prawny, przepis prawny, chiński język prawny 


\section{Wstęp}

Przepisy każdego aktu prawotwórczego, czyli także przepisy każdej ustawy powinny być komunikatywne dla odbiorcy. Jednym ze sposobów osiagnięcia komunikatywności przepisów jest zachowanie ich przejrzystej konstrukcji (Wronkowska i Zieliński 2007: 29). Polskich prawodawców obowiązuje zbiór dyrektyw techniki prawodawczej z 2002 roku, w którym określono formuły konstruowania aktów prawodawczych oraz przedstawiono wskazówki dotyczące redagowania poszczególnych typów przepisów, w tym także katalog środków stosowanych w poszczególnych przepisach. Chińskie regulacje dotyczące podstawowych zasad legislacji (立法制度 lifă zhìù) - tj.:

中华人民共和国立法法 (Zhōnghuárénmíngònghéguó liffă fă) (2000.3.15), procedury sporządzania ustaw - 行政法规制定程序条例 (făguī zhìding chéngxù) (2001. 11. 16)

规章制定程序条例 (guīzhāng zhìding chéngxù tiáoli) (2001. 11. 16),

法规规章备案条例 (făgū̄ guīzhāng bèi'àn tiáoli) (2001. 12.14)

- nie zawierają podobnych zasad techniki prawodawczej.

Zgodnie z paragrafem 11.1 Zasad techniki prawodawczej każda ustawa poza tzw. przepisami merytorycznymi zawierać musi przepisy o wejściu ustawy w życie, a także przepisy przejściowe lub dostosowujące oraz przepisy uchylające, jeśli normuje dziedzinę spraw, która została już wcześniej uregulowana. Ustawa może zawierać ponadto przepisy o zmianie przepisów obowiązujących (przepisy nowelizujące) oraz przepisy o wygaśnięciu swojej mocy obowiązującej. Przepisy uchylające, przepisy o wejściu ustawy w życie i przepisy o wygaśnięciu mocy ustawy tworzą zgodnie z paragrafem 27.1 ZTP przepisy końcowe.

W niniejszym artykule dokonano próby wyodrębnienia (i) przepisów o zmianie przepisów obowiązujących, (ii) przepisów odsyłających oraz (iii) wybranych przepisów końcowych. Przepisy przejściowe i dostosowujące oraz wybrane przepisy merytoryczne ze względu na swą złożoność omówione zostaną w osobnym artykule.

\section{Metoda badawcza i korpus badawczy}

Ponieważ autorka artykułu nie znalazła innego rozporządzenia, które zawiera katalog środków stosowanych w przepisach o zmianie przepisów obowiązujących, przepisów odsyłających i przepisach końcowych dokonała analizy wybranych chińskich ustaw celem wyodrębnienia środków typowych dla wymienionych przepisów i przetłumaczenia ich na język polski.

Do analizy wykorzystano wybrane ustawy chińskie i polskie zawierające (i) przepisy o zmianie przepisów obowiązujących, (ii) przepisy odsyłające i (iii) przepisy końcowe, które w rozumieniu niniejszego artykułu stanowią teksty paralelne.

Za teksty paralelne uznaje się teksty w różnych językach, które zostały stworzone przez ich kompetentnych użytkowników natywnych, nie są tłumaczeniem i dotyczą możliwie podobnego tematu i pełnią tę samą funkcję komunikacyjną, czyli są 
tekstami tego samego rodzaju (Göpferich 1998). Podobna definicja tekstów paralelnych sformułowana przez Snell-Hornby (1990: 10 w: Šarčević, 2000: 21-22) zawiera dodatkowo informację, że teksty paralelne powstają niezależnie od siebie w porównywalnej sytuacji. W zakresie badań terminologicznych i thumaczeniowych teksty paralelne należą do najważniejszych źródel, nie tylko w trakcie przygotowywania materiałów terminologicznych, ale także w zapewnianiu ekwiwalencji (Albrecht J. 2005: 170). Delisle (1999: 166) - twórca teorii tekstów paralelnych tekstem paralelnym określa $a$ text that represents the same text type as the source text lub a text that treats the same as closely related topic in the same field and that serves as a source for the <mots justes $>$ and terms that should ideally be incorporated into the target text to ensure collocational cohesion. Istnieje również drugi typ tekstów paralelnych, do których Matulewska (2010: 59) zalicza teksty źródłowe czy też zbiory wraz $\mathrm{z}$ ich tłumaczeniami na język docelowy.

W tłumaczeniu wykorzystano model pragmatycznego tłumaczenia terminów prawnych Kierzkowskiej (zob. 2002: 87 i n.), oparty na teorii skoposu Vermeera. Założono, że odbiorcą tłumaczenia będzie odbiorca daleki (zob. Kierzkowska 2002: 89) i zastosowano strategię dla odbiorcy dalekiego (ang. TLOT). Wyodrębnione $\mathrm{z}$ chińskich ustaw środki charakterystyczne dla wybranych typów przepisów przetłumaczono stosując ekwiwalencję konotacyjną (zob. Kierzkowska 2002: 95), odnosząc je do środków występujących w paralelnych przepisach ustawodawstwa polskiego i określonych częściowo w Zasadach techniki Prawodawczej.

\section{Wykaz skrótów:}

ChRL - Chińska Republika Ludowa

ZTP - Zasady Techniki Prawodawczej

TLOT - strategia thumaczeniowa dla odbiorcy dalekiego (ang. Target Language Oriented Translation)

\section{Przepisy o zmianie przepisów obowiązujących (przepisy nowelizujące)}

Przepisy o zmianie przepisów obowiązujących, czyli przepisy nowelizujące zalicza się do zbioru przepisów merytorycznych (zob. § 16-20 ZTP). Funkcją ich jest jak sama nazwa wskazuje zmiana obowiązujących przepisów. Zmiana dotyczy treści lub brzmienia określonego obowiązującego już przepisu bądź polega na dodaniu jakiegoś przepisu (Wronkowska, Zieliński 2007: 29).

W badanym korpusie składającym się $\mathrm{z}$ wybranych chińskich ustaw zawierających przepisy nowelizujące wyodrębniono następujące środki stosowane w przepisach o zmianie przepisów obowiązujących: 
Tabela 1. Katalog środków stosowanych w przepisach o zmianie przepisów obowiązujących

\begin{tabular}{|c|c|c|}
\hline Środki w języku chińskim & Transkrypcja pinyin & $\begin{array}{c}\text { Tłumaczenie na język } \\
\text { polski }\end{array}$ \\
\hline 对...作出修 & duì...zuòch $\bar{u} x i \bar{u}$ & $\begin{array}{l}\text { TLOT: w ... wprowadza } \\
\text { się zmiany }\end{array}$ \\
\hline 第...条修改为 ... & dì...tiāo xīügăi wèi... & $\begin{array}{l}\text { TLOT: artykuł ... } \\
\text { otrzymuje brzmienie ... }\end{array}$ \\
\hline 将...的“...”修改为 “...” & $\begin{array}{l}\text { jiāng...de ,,...” xiūgăi } \\
\text { wèi ,...." }\end{array}$ & $\begin{array}{l}\text { TLOT: wyraz „...” } \\
\text { występujący w ... } \\
\text { zastępuje się użytym w } \\
\text { odpowiednim przypadku } \\
\text { wyrazem / użytymi w } \\
\text { odpowiednich } \\
\text { przypadkach wyrazami } \\
\ldots . . .\end{array}$ \\
\hline 第...款修改为 ... & dì...kuăn xīugăi wèi... & $\begin{array}{l}\text { TLOT: ustęp ... } \\
\text { otrzymuje brzmienie ... }\end{array}$ \\
\hline 在...中增加 ...款 , 作为 ... & zài... zēengjiāa ... kuăn, & $\begin{array}{l}\text { TLOT: w... dodaje się } \\
\text { ustęp ... w następującym } \\
\text { brzmieniu ... }\end{array}$ \\
\hline 增加...条 , 作为 ... & $\begin{array}{l}\text { zēngjiā ... tiāo, zuòwéi } \\
\ldots\end{array}$ & $\begin{array}{l}\text { TLOT: dodaje się artykuł } \\
\ldots \text { w następującym } \\
\text { brzmieniu ... }\end{array}$ \\
\hline 增加...项, 作为 第...项 & $\begin{array}{l}\text { zèngjiā ... xiàng, zuòwéi } \\
\ldots\end{array}$ & $\begin{array}{l}\text { TLOT: dodaje się punkt } \\
\ldots \text { W następującym } \\
\text { brzmieniu ... }\end{array}$ \\
\hline
\end{tabular}

Poniżej ukazano przykłady chińskich przepisów o zmianie przepisów obowiązujących:

第十一届全国人民代表大会常务委员会第十次会议决定：

一、对下列法律中明显不适应社会主义市场经济和社会发展要求的规定作出

修：

1 . 将《中华人民共和国民法通则》第七条修改为 : “民事活动应当尊重社会

公德，不得损害社会公共利益，扰乱社会经济秩序。”

[Stały Komitet Ogólnochińskiego Zgromadzenia Przedstawicieli Ludowych XI kadencji uchwalił na X sesji co następuje:

I. W przepisach poniżej wymienionych ustaw, nie odpowiadających wymaganiom socjalistycznej gospodarki rynkowej i rozwojowi społeczeństwa wprowadza się następujące zmiany: 
1. Artykuł 7 Ustawo o ogólnych regułach prawa cywilnego otrzymuje brzmienie: „Czynności cywilnoprawne powinny być $\mathrm{w}$ zgodzie z poszanowaniem współżycia społecznego i nie mogą szkodzić interesowi publicznemu oraz zakłócać porządku społeczno-ekonomicznego". $]^{10}$

\section{(...)对下列法律和法律解释中关于“征用”的规定作出修改}

\section{( - ) 将下列法律和法律解释中的“征用”修改为“征收、征用”}

\section{《中华人民共和国森林法》第十八条}

[(...) W poniżej wymienionych przepisach ustaw i w wykładni prawa dotyczącej ,powołania” wprowadza się następujące zmiany:

(1) W poniżej wymienionych przepisach ustaw i w wykładni prawa wyraz ,powołanie" zastępuje się użytymi w odpowiednich przypadkach wyrazami ,pobór, powołanie"

„Ustawa o lasach Chińskiej Republiki Ludowej” artykuł 18 $]^{11}$

二、在第二条中增加三款，作为第二、三、四款 :

“发明，是指对产品、方法或者其改进所提出的新的技术方案。

实用新型，是指对产品的形状、构造或者其结合所提出的适于实用的新的技

术方案。

外观设计，是指对产品的形状、图案或者其结合以及色彩与形状、图案的结

合所作出的富有美感并适于工业应用的新设计。”

[W artykule drugim dodaje się ustęp 2 , ustęp 3 i ustęp 4 w następującym brzmieniu:

„Za wynalazki uważa się wszelkie nowe projekty techniczne w zakresie produktu oraz jego działania i ulepszania."

"Za wzory użytkowe uważa się wszelkie nowe projekty techniczne w zakresie kształtu i struktury produktu lub ich kombinacji, które dotyczą użytku praktycznego."

„Za wzornictwo uważa się wszelki nowy projekt produktu kształtu, wzoru lub ich kombinację, jak również kombinację koloru i kształtu lub wzór produktu, który wpływa na odczucia estetyczne i nadaje się do zastosowania przemysłowego." $]^{12}$

\section{Przepisy odsylające}

Przepisy odsyłające wskazują na postanowienia zawarte w innym obowiązującym już przepisie lub przepisach. Funkcją ich jest odesłanie do rozwiązań merytorycznych $\mathrm{w}$ innych przepisach $\mathrm{w}$ dosłownym tego słowa znaczeniu lub tylko przywołanie innego

\footnotetext{
${ }^{10}$ 中华人民共和国主席令，第十八号

${ }^{11}$ 中华人民共和国主席令，第十八号

12 《中华人民共和国专利法》第三次修改解析
} 
przepisu lub innych przepisów, które jedynie uzupełniają rozwiązania przewidziane w przepisie odsyłającym (Wronkowska, Zieliński 2007: 171). Wyróżnia się dwa typy przepisów odsyłających:

i. odesłanie wewnętrzne,

ii. odesłanie zewnętrzne.

Odesłanie wewnętrzne polega na odesłaniu do innego przepisu lub innych przepisów tej samej ustawy, natomiast odesłanie wewnętrzne polega na odesłaniu do przepisu lub przepisów zawartych w innej ustawie lub innych ustawach (ibidem).

Podobne do przepisów odsyłających są tzw. przepisy blankietowe, które różnia się od tych pierwszych tym, że nie wyrażają obowiązków czy uprawnień, ale określaja w jaki sposób mają być określone czyjeś obowiązki lub uprawnienia (ibidem).

$\mathrm{W}$ badanym korpusie składającym się $\mathrm{z}$ wybranych chińskich ustaw zawierających przepisy odsyłające wyodrębniono następujące środki:

Tabela 2. Katalog środków stosowanych w przepisach odsyłających

\begin{tabular}{|c|c|c|}
\hline Środki w języku chińskim & Transkrypcja pinyin & $\begin{array}{c}\text { Tłumaczenie na język } \\
\text { polski }\end{array}$ \\
\hline 对本法第...条所列... & $\begin{array}{l}\text { dùi bĕn fă dì ... tiāo } \\
\text { suŏliè ... }\end{array}$ & $\begin{array}{l}\text { wymienione } w \text { art. ... } \\
\text { niniejszego prawa ... }\end{array}$ \\
\hline ... 以本法第...条规定 & $\begin{array}{l}\text { y̌̆ bĕn fă dì ... tiāo } \\
\text { guīding ... }\end{array}$ & $\begin{array}{l}\text {... określone w art. ... } \\
\text { niniejszego prawa... }\end{array}$ \\
\hline 依照...的规定 & yīzhào de ... guīdìng & zgodnie z przepisami ... \\
\hline
\end{tabular}

第三十三条

本法所称抵押，是指债务人或者第三人不转移对本法第三十四条所列财产的

占有，将该财产作为债权的担保。(...)

[SLOT: art.33. W niniejszym prawie hipoteka oznacza, że dłużnik lub strona trzecia zabezpiecza wierzytelności wierzyciela prawem własności do rzeczy bez jej przekazania wymienionym $w$ art. 35 niniejszego prawa. $]^{13}$

第四十一条

当事人以本法第四十二条规定的财产抵押的，应当办理抵押物登记，抵押合

同自登记之日起生效。

[art.41. Strona ustanawiająca hipotekę na własności do rzeczy określonej w art. 42 tego prawa, rejestruje rzecz, na której ustanowiła hipotekę, a umowa hipoteczna wchodzi w życie z dniem rejestracji. ${ }^{14}$

13 中华人民共和国担保法 


\section{第二条}

扰乱公共秩序，妨害公共安全，侵犯人身权利、财产权利，妨害社会管理，

具有社会危害性，依照《中华人民共和国刑法》的规定构成犯罪的，依法追

究刑事责任; 尚不够刑事处罚的，由公安机关依照本法给予治安管理处罚。

[art.2. Kto narusza porządek publiczny, zagraża bezpieczeństwu publicznemu, łamie prawa innych osób i prawo własności, utrudnia administrację społeczną, działa na szkodę społeczeństwa i zgodnie z przepisami Prawa Karnego Chińskiej

Republiki Ludowej stanowi przestępstwo, ponosi odpowiedzialność karną zgodnie z prawem. Jeżeli jego działanie nie podlega karze przewidzianej w prawie karnym, organ ochrony publicznej nałoży na niego karę za naruszanie bezpieczeństwa publicznego zgodnie z niniejszym prawem. $]^{15}$

\section{Przepisy końcowe}

Przepisy końcowe dotyczą zawsze innych przepisów prawnych, dlatego zamieszcza się je na końcu ustawy. Nie wyrażają norm generalnych i abstrakcyjnych, bo nie zamieszcza się w nich postanowień innych niż dotyczących uchylenia lub wprowadzenie w życie określonych przepisów. Są zatem aktami niepowtarzalnymi. Pozwalają ustalić aktualne teksty prawne, a przez to odgrywają istotną rolę $\mathrm{w}$ procesie wykładni prawa (Wronkowska, Zieliński 2007: 59-60).

Zgodnie z paragrafem 27.1 ZTP do przepisów końcowych zalicza się:

i. przepisy uchylające,

ii. przepisy o wejściu ustawy w życie,

iii. przepisy o wygaśnięciu mocy ustawy.

Poniżej zamieszczono informacje dotyczące częściej stosowanych przepisów końcowych, tj. przepisów uchylających i przepisów o wygaśnięciu mocy ustawy. Przepisy o wygaśnięciu mocy obowiązującej ustawy zamieszcza się tylko w tych ustawach, które mają obwiązywać w ograniczonym czasie. Przepisy te określają termin, przy czym nie może być on określony przez wskazanie wystapienia pewnych okoliczności (zob. §40.1 ZTP). Rzadko się zdarza by ustawodawca w momencie wydawania ustawy wyznaczał końcowy moment jej obowiązywania. Dzieje się tak gdy dany akt prawny normuje wyjątkową sytuację społeczna, albo gdy ma charakter tzw. ustawy okresowej (której okres obowiązywania można pod jego koniec przedłużyć) (Wronkowska, Zieliński 2007: 83). Ponieważ przepisy o wygaśnięciu mocy ustawy występują stosunkowo rzadko pominięto je w niniejszym artykule.

\footnotetext{
14 中华人民共和国担保法

15 中华人民共和国治安管理处罚法
} 


\section{Przepisy uchylajace}

Przepisy uchylające uchylaja inne przepisy prawne, które są w nich wyczerpująco wymienione - całe ustawy lub jedynie niektóre przepisy innego aktu prawotwórczego, zawarte $\mathrm{w}$ ustępach lub całych zbiorach przepisów ustawy, czyli np. w rozdziale lub dziale. Samo odmienne uregulowanie danej sprawy w nowej ustawie lub w nowym przepisie nie uchyla domyślnie istniejących już przepisów (Wronkowska, Zieliński 2007: $60)$.

W badanym korpusie składającym się $\mathrm{z}$ wybranych chińskich ustaw wyodrębniono następujące środki stosowane w przepisach uchylających:

Tabela 3. Katalog środków stosowanych w przepisach uchylających

\begin{tabular}{|l|l|l|}
\hline Środki w języku chińskim & Transkrypcja pinyin & Tłumaczenie na język polski \\
\hline$\ldots$ 废止 & $\ldots$ fèizh $\breve{~}$ & TLOT: ... traci moc \\
\hline 删去... & shāngqù ... & TLOT: uchyla się ... \\
\hline$\ldots$ 失效 & $\ldots$ shīxiào & TLOT: ... traci moc \\
\hline
\end{tabular}

Poniżej ukazano przykłady przepisów uchylających:

第四百二十八条本法自1999年10月1日起施行，《中华人民共和国经济合同法

》、《中华人民共和国涉外经济合同法》、 《中华人民共和国技术合同法》

同时废止。

[art. 428. Niniejsze prawo wchodzi w życie z dniem 1 października 1999 roku, jednocześnie uchyla się „Prawo umów ekonomicznych Chińskiej Republiki Ludowej”, „Prawo zagranicznych umów ekonomicznych Chińskiej Republiki Ludowej”, „Prawo umów z zakresu technologii Chińskiej Republiki Ludowej”.] ${ }^{16}$

第五十一条

本法自1981年1月1日起施行。1950 年5 月1 日颁行的《中华人民 共和国婚姻法》, 自本法施行之日起废止。

[art. 51. Niniejsze prawo wchodzi w życie z dniem 1 stycznia 1981 roku. Z dniem wejścia niniejszej ustawy w życie uchyla się „Prawo małżeńskie Chińskiej Republiki Ludowej" z dnia 1 maja 1950 r.] $]^{17}$

(...) 删去《中华人民共和国体育法》第四十七条。

[ (...) Uchyla się art. 47 „Prawa sportowego Chińskiej Republiki Ludowej”. $]^{18}$

\footnotetext{
16 中华人民共和国合同法

17 中华人民共和国婚姻法

18 中华人民共和国主席令, 第十八号
} 
删去第五十八条第一款第六项。

[Uchyla się artykuł 58 ustęp 1 punkt 6.] ${ }^{19}$

第六十四条

本法自1983 年 3 月 1 日起施行。1963 年 4 月 10 日国务院公布的《

商标管理条例》同时废止; 其他有关商标管理的规定，凡与本法抵触的，同

时失效。

本法施行以前已经注册的商标继续有效。

[art. 64. Niniejsze prawo wchodzi w życie z dniem 1 marca 1983 roku. Ogłoszone 10 kwietnia 1963 roku przez Radę Narodową „Przepisy o zarządzaniu znakami handlowymi” równocześnie tracą moc; inne postanowienia dotyczące zarządzania znakami handlowymi, które są sprzeczne z niniejszym prawem, jednocześnie tracą moc.

Znaki handlowe zarejestrowane przed wejściem tego prawa $\mathrm{w}$ życie nadal obowiazuja. $]^{20}$

\section{Przepisy o wejściu ustawy w życie}

Zgodnie z paragrafem 11 ZTP każda ustawa powinna zawierać postanowienia o jej wejściu w życie. Wyjątek stanowi wydanie do danej ustawy wstawy wprowadzającej (zob. § 31 ZTP; Wronkowska, Zieliński 2007: 69). Zasadniczo ustawodawca wskazuje też termin wejścia ustawy w życie.

W badanym korpusie składającym się $\mathrm{z}$ wybranych chińskich ustaw wyodrębniono następujące środki stosowane w przepisach o wejściu ustawy w życie:

Tabela 4. Katalog środków stosowanych w przepisach o wejściu ustawy w życie

\begin{tabular}{|l|l|l|}
\hline $\begin{array}{c}\text { Środki w języku } \\
\text { chińskim }\end{array}$ & \multicolumn{1}{|c|}{$\begin{array}{c}\text { Transkrypcja } \\
\text { pinyin }\end{array}$} & \multicolumn{1}{|c|}{ Tłumaczenie na język polski } \\
\hline$\ldots$ 起施行 & $\ldots q \check{l}$ sh $\operatorname{l} x$ xing & $\begin{array}{l}\text { TLOT: ... wchodzi w życie } / \ldots \\
\text { nabiera mocy, }\end{array}$ \\
\hline
\end{tabular}

Poniżej ukazano przykładowe przepisy o wejściu ustawy w życie:

第一百五十六条 本法自一九八七年一月一日起施行。

[art. 156. Niniejsze prawo wchodzi w życie z dniem 1 stycznia 1987 roku. $]^{21}$

第二百一十九条 本法自2006年1月1日起施行。

[art. 219. Niniejsze prawo wchodzi w życie $\mathrm{z}$ dniem 1 stycznia 2006 roku $]^{22}$

\footnotetext{
${ }^{19}$ 中华人民共和国主席令, 第十八号

${ }^{20}$ 中华人民共和国商标法

${ }^{21}$ 中华人民共和国民法通则
} 


\section{Przepisy o zakresie zastosowania}

Przepisy o zakresie zastosowania informują o tym jakie instytucje i sprawy są przez dany akt prawny regulowane, albo do jakich czynności dane prawo się stosuje.

W badanym korpusie składającym się $\mathrm{z}$ wybranych chińskich ustaw zawierających przepisy o zakresie zastosowania wyodrębniono następujące środki:

Tabela 5. Katalog środków stosowanych w przepisach o zakresie zastosowania

\begin{tabular}{|l|l|l|}
\hline $\begin{array}{c}\text { Środki w języku } \\
\text { chińskim }\end{array}$ & Transkrypcja pinyin & Tlumaczenie na język polski \\
\hline$\ldots$ 适用于... & $\ldots$ shìyòng ... & $\begin{array}{l}\text { TLOT: ... ma zastosowanie } \\
\text { do... }\end{array}$ \\
\hline 在...适用... & zài ... shìyòng ... & $\begin{array}{l}\text { w odniesieniu do ... stosuje się } \\
\ldots\end{array}$ \\
\hline
\end{tabular}

Poniżej ukazano przykładowe przepisy o zakresie zastosowania:

第二条。本法适用于中华人民共和国境内拍卖企业进行的拍卖活动。

[Art. 2. Niniejsze prawo ma zastosowanie do czynności aukcyjnych wykonanych przez domy aukcyjne w Chińskiej Republice Ludowej] $]^{23}$

第八条。在中华人民共和国领域内的民事活动，适用中华人民共和国法律， 法律另有规定的除外。

[Art. 8. Do czynności cywilnoprawnych wykonywanych w Chińskiej Republice Ludowej ma zastosowanie Prawo Chińskiej Republiki Ludowej] ${ }^{24}$

\footnotetext{
22 公司法

${ }^{23}$ 中华人民共和国拍卖法

http://www.chinalawedu.com/new/23223a23228a2010/20101223shangf1 13455.shtml

${ }^{24}$ 中华人民共和国民法通则
} 


\section{Uwagi końcowe}

$\mathrm{Na}$ podstawie analizy wybranych tekstów paralelnych wyodrębniono środki w chińskich przepisach nowelizujących, odsyłających, uchylających, przepisach o wejściu ustawy w życie i o zakresie zastosowania. Choć autorka artykułu nie znalazła wśród chińskich przepisów dotyczących tworzenia i struktury aktu prawnego przepisów podobnych do przepisów ZTP, które określałyby typy przepisów w aktach prawotwórczych i stosowanych w nich środków językowych, to wyniki analizy tekstów paralelnych pozwala stwierdzić, że chiński ustawodawca tworząc przepisy stosuje swoisty i mało rozbudowany katolog środków językowych. 


\section{Bibliografia}

Albrecht J. 2005. Übersetzung und Linguistik. Grundlagen der Übersetzungsforschung. Tübingen: Gunter Narr Verlag.

Göpferich S. 1998. Paralleltexte. In: Snell-Hornby et alii (Hgg.), Handbuch Translation. Tübingen. Art. 30.

Kierzkowska D. 2002. Ttumaczenie prawnicze. Warszawa: Wydawnictwo TEPIS Polskiego Towarzystwa Tłumaczy Ekonomicznych, Prawniczych i Sądowych.

Matulewska A. 2010. Teksty paralelne a ustalanie konotatów i denotatów na potrzeby przekładu polsko-angielskiego. W: Legilingwistyka Porównawcza. Tom 3. Poznań: Zakład Graficzny Uniwersytetu im. A. Mickiewicza w Poznaniu.

Snell-Hornby M. 1990. „Slippery when wet”: Parallertexte als Übersetzungshilfe, In: Wills W. (Hg.) Der Deutschunterricht, Themenheft: Übersetzungswissenschaft, 10-16.

Šarčević, S. 2000. New approach to legal translation. The Hague: Kluwer Law International.

Wronkowska S., Zieliński M. 1997. Zasady techniki prawodawczej. Komentarz. Warszawa: Wydawnictwo Sejmowe.

\section{Źródła}

Rozporządzenie prezesa Rady Ministrów z dnia 20 czerwca 2002 r. w sprawie „Zasad techniki prawodawczej” Dz. U. 02.100.908.

中华人民共和国合同法 (@: http://www.gov.cn/banshi/2005-07/11/content_13695.htm, data dostępu: 06.2011).

中华人民共和国主席令，第十八号 (@: http://www.gov.cn/flfg/2009-08/27/content_ 1403326.htm, data dostęu: 05.2011).

《中华人民共和国专利法》第三次修改解析(@: http://www.chinalawedu.com/new/1300_23230_/2009_3_17_ma3484253331171390021 2565.shtml, data dostępu: 05.2011).

中华人民共和国担保法 (@: http://www.gov.cn/banshi/2005-09/01/content_68752.htm, data dostępu: 06.2011).

中华人民共和国婚姻法 (@: http://www.gov.cn/banshi/2005-05/25/content_847.htm, data dostępu: 05.2011).

中华人民共和国商标法 (@: http://www.lawtime.cn/faguizt/39.html, data dostępu: 06.2011).

中华人民共和国民法通则 (@:http://www.npc.gov.cn/wxzl/wxzl/2000-12/06/content_4470.htm).

中华人民共和国公司法 (@: http://www.gov.cn/ziliao/flfg/2005-10/28/content_85478.htm, data dostępu 12.2012).

中华人民共和国企业破产法 (@: http://www.gov.cn/flfg/2006-08/28/content_371296.htm, data dostępu: 12.2012).

中华人民共和国治安管理处罚法 (@: http://www.legaldaily.com.cn/misc/200602/16/content_267035.htm).

中华人民共和国拍卖法 (@: http://www.chinalawedu.com/new/23223a23228a2010 /20101223shangf1 13455.shtml, data dostępu 05.2011). 